\title{
Systematic Layout Planning (SLP) para Melhoria do Arranjo Físico de um Ambiente de
} Produção de Joias

Versão do autor aceita publicada online: 11 ago. 2021

Publicado online: 30 ago. 2021

Como citar esse artigo - American Psychological Association (APA): Marques, M. A. dos S., \& Salgado, C. C. R. (2021). Systematic Layout Planning (SLP) para melhoria do arranjo físico de um ambiente de produção de joias. Exacta. https://doi.org/10.5585/exactaep.2021.19329

\section{Mikaelly Anastácio dos Santos Marques \\ mikamarques99@gmail.com \\ https://orcid.org/0000-0002-7522-9868 \\ Universidade Federal da Paraíba - UFPB \\ Graduada em Administração pela Universidade Federal da Paraíba}

\section{Camila Cristina Rodrigues Salgado}

adm.camilarodrigues@ hotmail.com

http://orcid.org/0000-0002-2018-8763

Professora do Departamento de Ciências Sociais Aplicadas da Universidade Federal da Paraíba - DCSA/UFPB

Graduada em Administração pela Universidade Federal da Paraíba, Mestrado em Engenharia de Produção e Doutorado em Administração pela Universidade Federal do Rio Grande do Norte - UFRN

\section{Resumo}

Planejar o arranjo físico ou layout é uma maneira de melhorar o desempenho das organizações em termos de custos, utilização de espaço e fluxo de operações, adequando equipamentos, pessoas e materiais no ambiente de produção. Portanto, o objetivo deste artigo é propor melhorias ao arranjo físico de um ambiente de produção de joias através do método Systematic Layout Planning - SLP. Esse método auxilia nas decisões sobre como organizar e posicionar equipamentos e pessoal dentro do espaço disponível por meio de atividades interrelacionadas. Assim, realizou-se um estudo de caso de natureza aplicada e descritiva, com coleta de dados por meio de entrevistas semiestruturadas e de observação direta. A análise e interpretação dos dados foi conduzida de forma qualitativa de acordo com as fases do método SLP. Como resultado, foram feitas propostas de layouts e, respeitando as necessidades da organização analisada, apontou-se a mais adequada.

Palavras-chave: Layout. Planejamento Sistemático de Layout. Ambiente Produtivo. 


\title{
Production Environment
}

\begin{abstract}
Planning the physical arrangement or layout is a way to improve the performance of organizations in terms of costs, use of space and flow of operations, adapting equipment, people and materials in the production environment. Therefore, the objective of this article is to propose improvements to the physical arrangement of a jewelry production environment using the Systematic Layout Planning - SLP method. This method assists indecisions on how to organize and position equipment and personnel within the available space through interrelated activities. Thus, a case study of an applied and descriptive nature was carried out, with data collection through semi-structured interviews and direct obseryation. The analysis and interpretation of the data was conducted in a qualitative way according to the phases of the SLP method. As a result, proposals for layouts were made and, respecting the needs of the analyzed organization, the most appropriate was pointed out.
\end{abstract}

Keywords: Layout. Systematic Layout Planning. Productive Environment.

\section{Introdução}

Considerando que as empresas precisam atingir margens de lucro significativas, reduzindo custos e retrabalho, tem-se que o desenho do arranjo físico ou layout é uma das decisões que impactam diretamente nessa empreitada, principalmente diante de um mercado extremamente competitivo (Lermen, Campos, Cóelho, Matias, \& Echeveste, 2020; Erik \& Kuvvetli, 2021). Planejar o layout é decidir onde as estações de trabalho, equipamentos, máquinas e pessoas serão endereçados, de forma a facilitar o fluxo de materiais e pessoas dentro do ambiente produtivo (Moreira, 2012). Esta tarefa exige tempo e comprometimento dos envolvidos, podendo se tornar complexa a depender das dimensões físicas dos recursos transformadores, assumindo, portanto, cunho estratégico, além de proporcionar economia e incremento da produção (Giraldeli et al., 2018).

Um layout adequado é capaz de otimizar os processos produtivos, aproveitando o ambiente de produção de maneira eficiente, porém é essencial usar métodos que auxiliem na tomada de decisão para a sua elaboração. Nessa perspectiva, destaca-se a utilização do Systematic Layout Planning (SLP), uma metodologia que visualiza os recursos disponíveis no processo de produção de forma estruturada, para o melhor uso de seu espaço (Muther, 2012).

Conforme apontam Liu, Hwang, Hsieh, Liang e Chuang (2016), estudos anteriores indicaram que o SLP é uma ferramenta comprovada para fornecer diretrizes de design de layout na prática. Neste sentido, podem ser citados estudos que utilizaram o SLP como método 
principal para explorar questões relativas aos layouts, de forma a contribuir para a melhoria dos métodos de produção, como os de Fahad, Naqvi, Atir, Zubair e Shehzad (2017), Giraldeli et al. (2018) e Liu et al. (2016).

Fahad et al. (2017) apresentam um estudo de caso sobre uma fábrica de pequeno porte, ilustrando, a partir do emprego do SLP e de ferramentas enxutas para projetar alternativas de layout, a importância do design de layout na economia de energia. Já Giraldeli et al. (2018) propuseram a adequação de layout para uma empresa do setor elétrico, com a utilização do SLP, resultando em melhorias de diferentes problemas, como a movimentação excessiva de materiais, sequenciamento do fluxo de operações desordenadas e má utilização do espaço físico.

Por fim, o trabalho de Liu et al. (2016) investigou o projeto de interface de um sistema de alarme digital por meio da análise do processo de diagnóstico de informações operacionais para garantir a segurança em usinas nucleares. Eles utilizaram o SLP para modificar o design das janelas de alarme, visando melhorar a interface do sistema humano. Estes exemplos mostram que investigações que possuem o método SLP como base podem trazer contribuições inquestionáveis e pertinentes à academia e às organizações.

Um exemplo de mercado influenciado por um layout propício à fabricação de seus produtos é o setor joalheiro, que apresenta uma estrutura de produção cautelosa na produção de joias em geral e tem se apresentado como um mercado atrativo e que vem ganhando espaço devido a sua diferenciação em produtos e confecção de peças únicas e inovadoras. Assim, a aplicação de novas tecnologias e planejamento de layout para atender às especificações da fabricação de joias é pertinente nesse tipo de mercado.

Diante do exposto, o presente artigo tem como objetivo propor melhorias ao arranjo físico de um ambiente de produção de joias através do método Systematic Layout Planning - SLP. Busca-se aqui identificar oportunidades de melhoria, com vistas à otimização dos processos, minimização de esforços e aumento da competitividade. Tal proposta é relevante diante da ausência de trabalhos que utilizem o SLP para auxiliar nas decisões sobre o arranjo físico na produção de joias.

Além desta introdução, o restante deste artigo está estruturado da seguinte forma: a primeira seção discute o referencial teórico, que buscou reunir os principais autores e os textos fundamentais para a compreensão do tema da pesquisa, como arranjo físico e o método SLP; logo depois os procedimentos metodológicos adotados são descritos, seguido da apresentação resultados obtidos; e por fim, apresentam-se as considerações finais e sugestões para estudos futuros. 


\section{Referencial Teórico}

\subsection{Arranjo Físico}

O arranjo físico ou layout planeja a forma como será organizado o ambiente de trabalho, de maneira a considerar que os funcionários possam trabalhar de modo agradável e com segurança, evitando movimentos desnecessários. Ademais, Moreira (2012) alerta que o arranjo físico vai além do posicionamento dos recursos transformadores, pois deve-se considerar que o arranjo físico adequado corresponda às necessidades e os objetivos da organização.

Nesse sentido, o arranjo físico pode afetar direta e indiretamente os custos de produção, a produtividade e a eficiência da organização caso o seu planejamento esteja inadequado, causando inconveniências aos funcionários e aos clientes (Vieira, Fernandes, Cortez, Nunes, \& Araújo, 2014). Slack, Chambers e Johnston (2009) afirmam que decidir o arranjo físico é importante, pois, caso o arranjo esteja errado, serão gerados fluxos muito longos, confusos e, consequentemente, filas de clientes, aumento no tempo de processo e insatisfação. Além disso, o rearranjo físico pode gerar mais custos e interrupções no funcionamento da operação, levando a perdas de produção.

Na mesma linha, Moreira (2012) aponta três motivos que tornam as decisões sobre arranjo físico importantes: o arranjo físico pode afetar a capacidade da instalação e a produtividade da operação; mudanças no layout podem gerar desperdícios de dinheiro e; mudanças podem apresentar altos custos e dificuldades técnicas de reversão futura.

Para a elaboração do arranjo físico, deve-se considerar oito objetivos essenciais para a operação (Slack, Brandon-Jones, \& Johnston, 2018): segurança inerente; extensão do fluxo; clareza do fluxo; conforto para os funcionários; coordenação gerencial; acessibilidade; uso do espaço; e flexibilidade.

No que se refere aos tipos de arranjo físico, sabe-se que sua definição dependerá do fluxo operacional a ser alcançado. Em síntese, a literatura apresenta a seguinte tipologia:

a) Arranjo físico posicional: O arranjo físico posicional ou de posição fixa é aquele cujo produto fica parado, enquanto as máquinas, pessoas e equipamentos deslocam-se e movimentam-se ao seu redor (Cardoso, 2012). Trata-se de um arranjo desenvolvido para produtos pesados e customizados, como aviões e navios, não sendo conveniente movê-los durante o processo de fabricação;

b) Arranjo físico Funcional: $\mathrm{O}$ arranjo físico funcional, também conhecido como arranjo físico por processo, é aquele em que processos similares são localizados próximos uns dos 
outros (Slack et al., 2018). Os recursos com necessidades similares são agrupados em departamentos funcionais, nos quais caminhos serão percorridos de acordo com a necessidade da operação (Moreira, 2012);

c) Arranjo físico Celular: O arranjo físico celular é aquele no qual os recursos transformados, quando entram na operação, são pré-selecionados a se movimentar a uma parte específica da operação, a "célula", em que os recursos transformadores estão localizados para atender suas necessidades (Slack et al., 2018);

d) Arranjo físico por Produto: O arranjo físico por produto, também chamado de "em linha" ou linear, é um tipo de layout destinado a grandes produções, que requerem operações sequenciadas para produzir grandes volumes de produtos, com alta padronização (Moreira, 2012). Os recursos transformados seguem um roteiro predefinido em um fluxo ào longo da linha de fácil controle (Slack et al., 2018).

Existem operações que podem combinar alguns ou todos os tipos de arranjo físico, que são projetados como arranjos físicos híbridos ou mistos para melhor atender às necessidades do processo (Slack et al., 2018). Para Gayam, Shanmuganandam e Vinodh (2020), qualquer que seja o tipo de layout, eles sempre são projetados visando a melhoria nas condições de área de trabalho, de forma a minimizar perdas e gerar bons resultados.

Segundo Corrêa e Corrêa (2009), o principal objetivo de decidir o melhor arranjo físico é o fato de que o mesmo suporta as estratégias competitivas da operação, ou seja, o arranjo físico escolhido deve estar alinhado com as estratégias da organização, com intuito de ajudar a aumentar seu desempenho competitivo. Para eles, um bom projeto de arranjo é aquele que facilita o movimento de pessoas e materiais, minimiza os custos e reduz os tempos de ciclo dentro da operação.

\subsection{Systematic Layout Planning (SLP)}

O método Systematic Layout Planning (SLP), um dos mais conhecidos para determinar arranjos físicos, foi desenvolvido por Richard Muther em 1961, presumindo que a localização das instalações, equipamentos e pessoal se dá principalmente com base em seu relacionamento mútuo (Van Donk \& Gaalman, 2004). O SLP é uma ferramenta que auxilia na tomada de decisão quanto ao melhor posicionamento de equipamentos e pessoal em uma instalação, uma vez que tem como objetivo reduzir custos e esforços desnecessários com fluxos racionais e o melhor uso do espaço (Muther, 2012). 
Para Ojaghi, Khademi, Yusof, Renani e Hassan (2015), trata-se de uma abordagem poderosa e de fácil aplicação, capaz de encontrar uma série de soluções para o layout. De forma geral, o SLP é estruturado em fases, que são: análise, pesquisa e seleção (Muther, 2012). Conforme explicam Flessas, Rizzardi, Tortorella, Denicol e Marodin (2014), na fase de análise há a coleta de informações sobre fluxos operacionais e atividades inter-relacionadas. Esse processo ocorre com a elaboração do diagrama "de-para", seguido do mapa de relacionamento, que indica a proximidade das atividades entre si, verificando os espaços necessários e disponíveis para cada processo. Já na fase de pesquisa, o diagrama de relacionamento é elaborado através do grau de aproximação das atividades em códigos de linha. Na fase de seleção, a melhor alternativa de layout é escolhida pela avaliação dos setores envolvidos.

Em síntese, na primeira fase coleta-se as informações fundamentais do processo, o fluxo das atividades e o relacionamento entre as atividades. Na segunda fase é elaborado o diagrama de interrelação, considerando algumas mudanças e limitações práticas para implementação do layout, de forma a identificar as atividades de aproximação através das relações de espaço e práticas.

Por fim, a última fase avalia e escolhe a melhor alternativa de layout para a organização. Assim, com todos os dados e informações necessários e seguindo adequadamente essas etapas da metodologia SLP, é possível solucionar problemas de layout, uma vez que o método está focado em soluções eficientes pară arranjos físicos (Yang, Su, \& Hsu, 2000).

\section{Procedimentos metodológicos}

Este artigo teve como objetivo propor melhorias ao arranjo físico de um ambiente de produção de joias através do método Systematic Layout Planning - SLP. Assim, para esta pesquisa, optou-se pela abordagem qualitativa, que, segundo Godoy (1995), é uma abordagem que permite informações mais profundas da organização, a fim de compreender o fenômeno a partir da percepção dos indivíduos nele envolvidos.

Como estratégia, foi utilizado o estudo de caso único, que busca investigar um fenômeno atual dentro de uma realidade, estudando o contexto em detalhes (Yin, 2010). Neste caso, uma joalheria localizada no município de Guarabira - PB foi a unidade organizacional a ser explorada, com foco em seu arranjo físico.

Levando em consideração a natureza da pesquisa, ela possui caráter aplicado, por contribuir de forma prática à solução de problemas concretos (Cervo, Bervian, \& Silva, 2006), ou seja, a proposição de melhorias ao arranjo físico de uma organização específica. Além disso, a 
pesquisa é descritiva, pois busca descrever as características de um determinado fenômeno (Gil, 2009), neste caso, as características do arranjo físico da empresa em questão.

Quanto à coleta de dados, as técnicas utilizadas foram: entrevista semiestruturada e observação direta. Para a primeira técnica, foi utilizado um roteiro de entrevistas semiestruturado, com o intuito de obter as informações necessárias de maneira flexível e aprofundada, por meio do diálogo entre o pesquisador e o entrevistado (Gil, 2009). Nesta ocasião, dois sujeitos foram entrevistados, o Diretor/proprietário e um funcionário, o assistente de produção, já que ambos são os responsáveis pela fabricação de joias no ambiente produtivo da organização, a oficina.

A entrevista foi gravada com o consentimento dos entrevistados, sendo posteriormente transcritas e analisadas. Sobre a segunda técnica, foram observados os postos de trabalho no que diz respeito à organização dos equipamentos, das ferramentas e do espaço disponível, bem como o percurso realizado pelos funcionários entre os postos. Por fim, para análise e interpretação dos dados, as fases e elementos sugeridos no método SLP (Figura 1) foram utilizados para analisar e propor melhorias ao layout, a partir dos dados coletados.

Figura 1. Sistema SLP

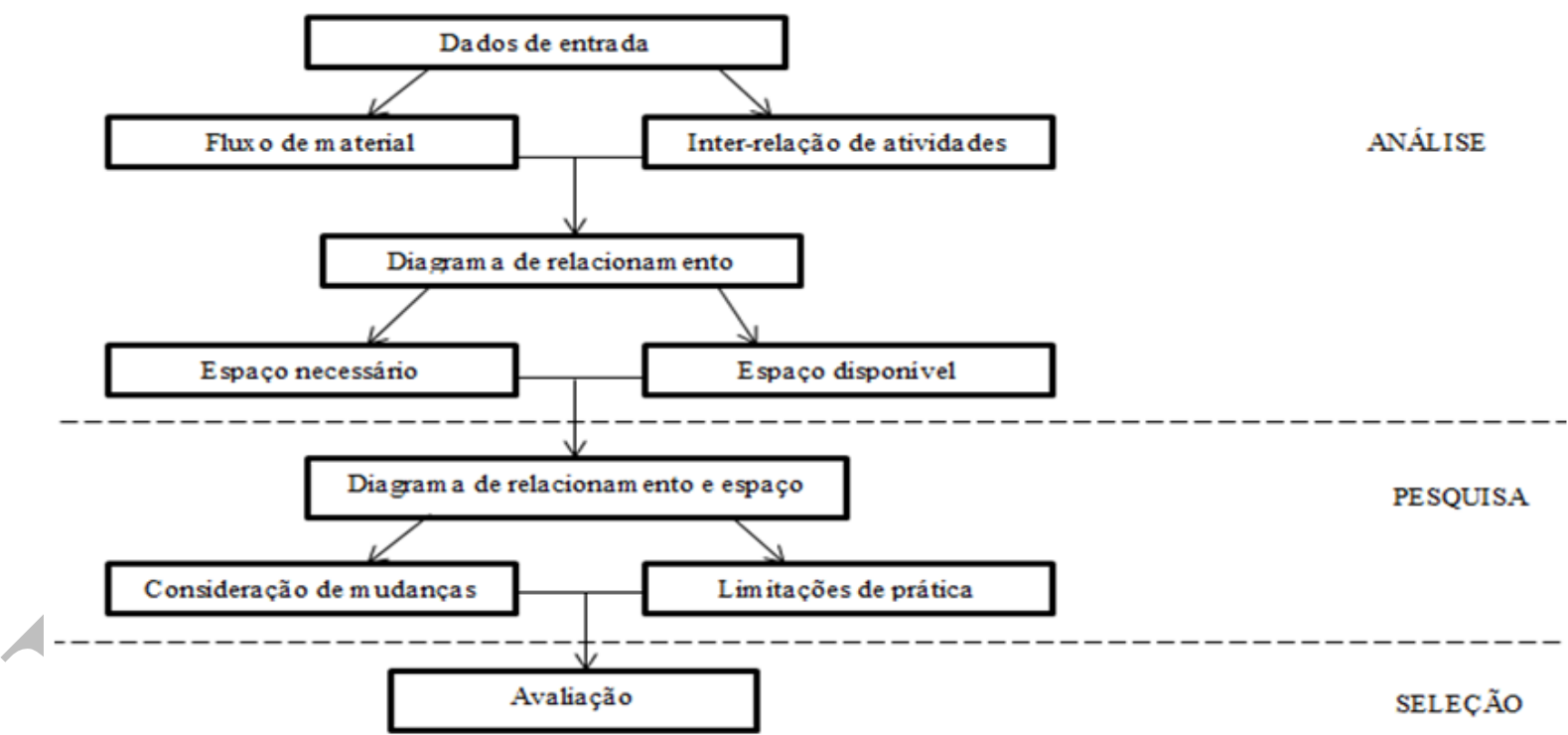

Fonte: Adaptado de Flessas, M., Rizzardi, V., Tortorella, G., Denicol, J., \& Marodin, G. (2014). Planejamento sistemático de layout aplicado à cozinha industrial de um restaurante temático. Revista Produção em foco, 4(2), 449-480.

\section{Análise e discussão dos resultados}

\subsection{Caracterização do ambiente produtivo da organização}

A organização estudada é uma joalheria e relojoaria que está no mercado há mais de 27 anos, cujo principal foco é a ourivesaria, ou seja, trabalha com metais preciosos (prata e ouro) para 
fabricação de joias. Durante os anos 2000 e 2004 a empresa passou por muitas mudanças devido à necessidade de aumento de espaço físico para atender seus clientes e suas demandas. A última mudança ocorreu em 2015, quando a organização passou para uma instalação maior e melhor localizada na cidade, já que precisava desse ambiente para acomodar seus equipamentos e atrair mais clientes.

De acordo com o proprietário, a oficina, local onde as peças são produzidas, foi dividida a partir de sua experiência no mercado (35 anos), tendo sido separada por processos de fabricação, a fim de facilitar o andamento da produção. Dessa forma, a estrutura produtiva da organização está dividida por Unidades de Processamento (UP), sendo cada uma delas responsável por um processo de fabricação de uma joia.

As UP's são usadas de acordo com o tipo de produto a ser fabricado, que são: alianças tradicionais, alianças trabalhadas e anéis de formatura. Na Figura 2 é possível observar o processo sequencial de cada joia produzida pela organização, bem como as unidades responsáveis por cada processamento.

Figura 2. Sequência de produção e unidades de processamento

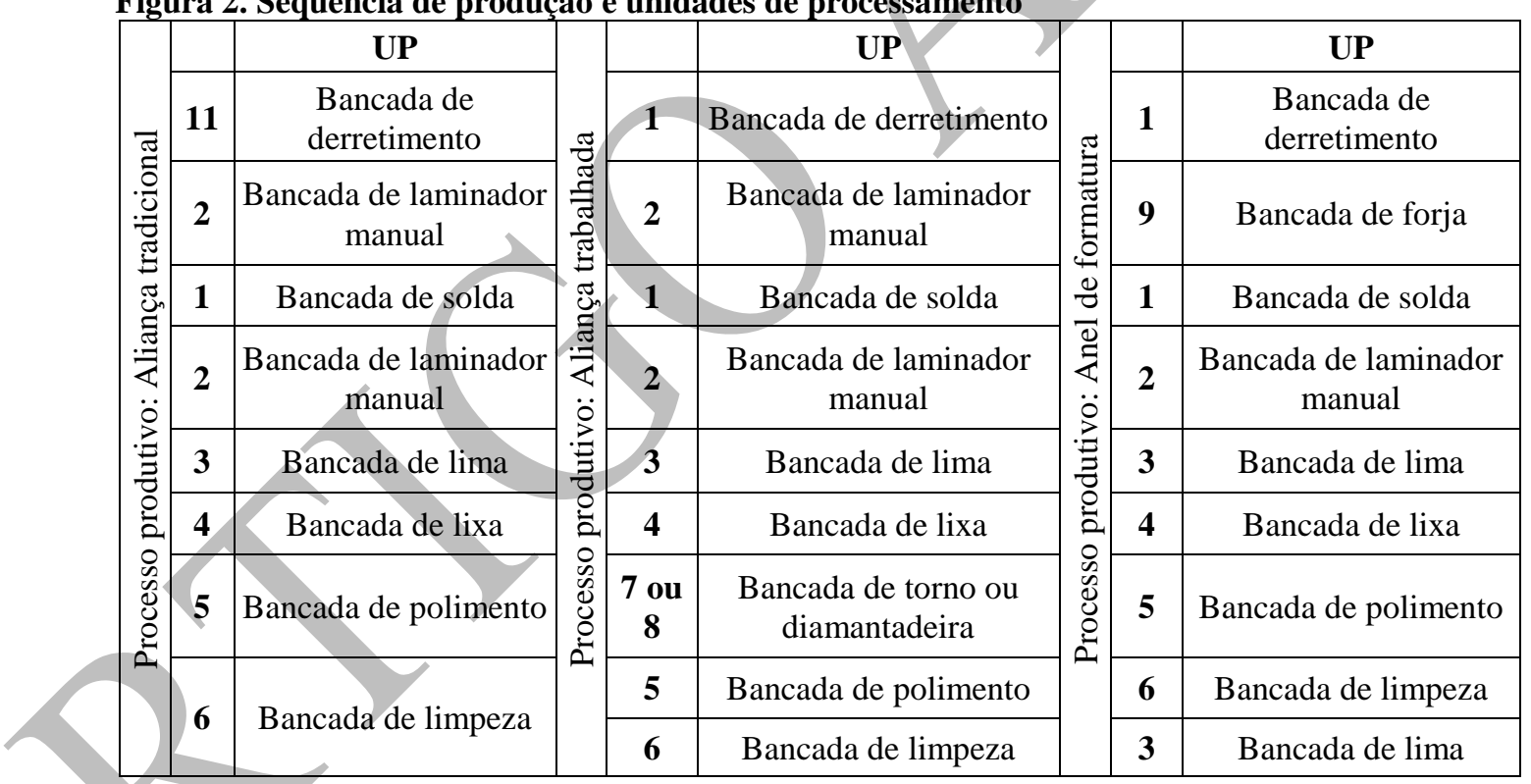

Fonte: Elaboração própria (2019).

Em síntese, o layout da organização é estruturado em Unidades de Processamento, onde os recursos transformados são movimentados de acordo com suas necessidades. Em outras palavras, cada joia produzida é submetida a um processo diferente em relação às demais, o que permite caracterizar o arranjo físico da organização como do tipo funcional ou por processo. A Figura 3 mostra o layout atual do ambiente produtivo da empresa e o caminho percorrido pelos recursos transformados entre os postos de trabalho. 
Figura 3. Layout atual da empresa

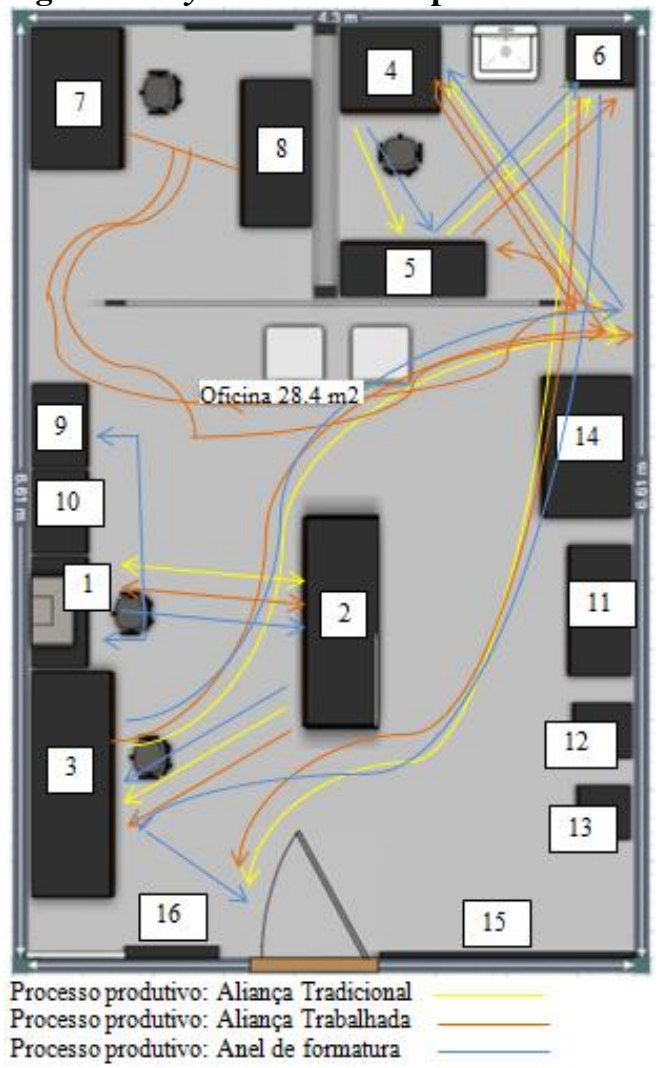

Fonte: Elaboração própria (2019).

De forma geral, o arranjo físico da empresa segue o que a literatura propõe, apresentando departamentos funcionais e flexíveis que a permite atendender diferentes demandas com peças distintas. No entanto, identificou-se a presença de cruzamentos nos fluxos que, por sua vez, devem ser tratados com muito cuidado para evitar que fluxos confusos se transformem em conflitos entre os funcionários, erros ou atrasos no processo produtivo.

\subsection{Aplicação do Método SLP}

Nesta etapa da pesquisa, foi aplicado o método SLP proposto por Muther (2012), seguindo as fases sugeridas para elaboração do arranjo físico. Na primeira fase, está a análise, cujas informações foram coletadas por meio da entrevista e da observação:

a) Dados de entrada: a empresa produz três tipos de produtos (alianças tradicionais, alianças trabalhadas e anéis de formatura); a quantidade desses produtos depende da época e o serviço solicitado pelo cliente, com média de produção de 5 a 10 pares de alianças por semana, segundo os entrevistados; o roteiro dos processos de produção é diferente para cada tipo de peça produzida; nos serviços de suporte, a empresa possui um lavatório no ambiente produtivo, porém é pouco utilizado, pois os funcionários utilizam o lavatório que fica fora 
desse ambiente e há prateleiras auxiliares que armazenam moldes e produtos químicos; o tempo de produção é de 45 minutos por joia produzida, em média.

b) Fluxo de materiais: o ambiente produtivo possui uma porta de vidro para entrada e saída de pessoas e materiais, e mais duas passagens entre os postos de trabalho. Assim, o fluxo de materiais entre cada UP que ocorre na fabricação dos três tipos de joias é mostrado no diagrama "de-para" apresentado na Figura 4.

Figura 4. Diagrama "de-para" da organização

\begin{tabular}{|c|c|c|c|c|c|c|c|c|c|}
\cline { 2 - 10 } \multicolumn{1}{c|}{} & PARA & $\mathbf{1}$ & $\mathbf{2}$ & $\mathbf{3}$ & $\mathbf{4}$ & $\mathbf{5}$ & $\mathbf{6}$ & $\mathbf{7 ~ o u ~ 8}$ & $\mathbf{9}$ \\
\hline \multirow{5}{*}{ DE } & $\mathbf{1}$ & & 5 & 0 & 0 & 0 & 0 & 0 & 1 \\
\cline { 2 - 11 } & $\mathbf{2}$ & 2 & & 3 & 0 & 0 & 0 & 0 & 0 \\
\cline { 2 - 10 } & $\mathbf{3}$ & 0 & 0 & & 3 & 0 & 0 & 0 & 0 \\
\cline { 2 - 10 } & $\mathbf{4}$ & 0 & 0 & 0 & & 2 & 0 & 1 & 0 \\
\cline { 2 - 10 } & $\mathbf{5}$ & 0 & 0 & 0 & 0 & & 3 & 0 & 0 \\
\cline { 2 - 10 } & $\mathbf{6}$ & 0 & 0 & 1 & 0 & 0 & & 0 & 0 \\
\cline { 2 - 10 } & $\mathbf{7}$ & 0 & 0 & 0 & 0 & 1 & 0 & 0 & 0 \\
\hline
\end{tabular}

Fonte: Elaboração própria (2019).

A Figura 4 representa, portanto, o fluxo de materiais referente a uma peça ou um par de cada produto fabricado pela empresa. Assim, é possível perceber que há uma intensidade de movimentação entre as UP's 1 e 2 , indicando que a "base" da peça precisa retornar a esses processos até que mesma esteja pronta para avançar aos demais processamentos e finalizar sua produção.

c) Inter-relação das atividades: $\propto$ diagrama de relacionamento foi utilizado para identificar a proximidade das atividades e sua importância no processo produtivo, como mostra a Figura 5.

Figura 5. Diagrama de relacionamento do ambiente produtivo

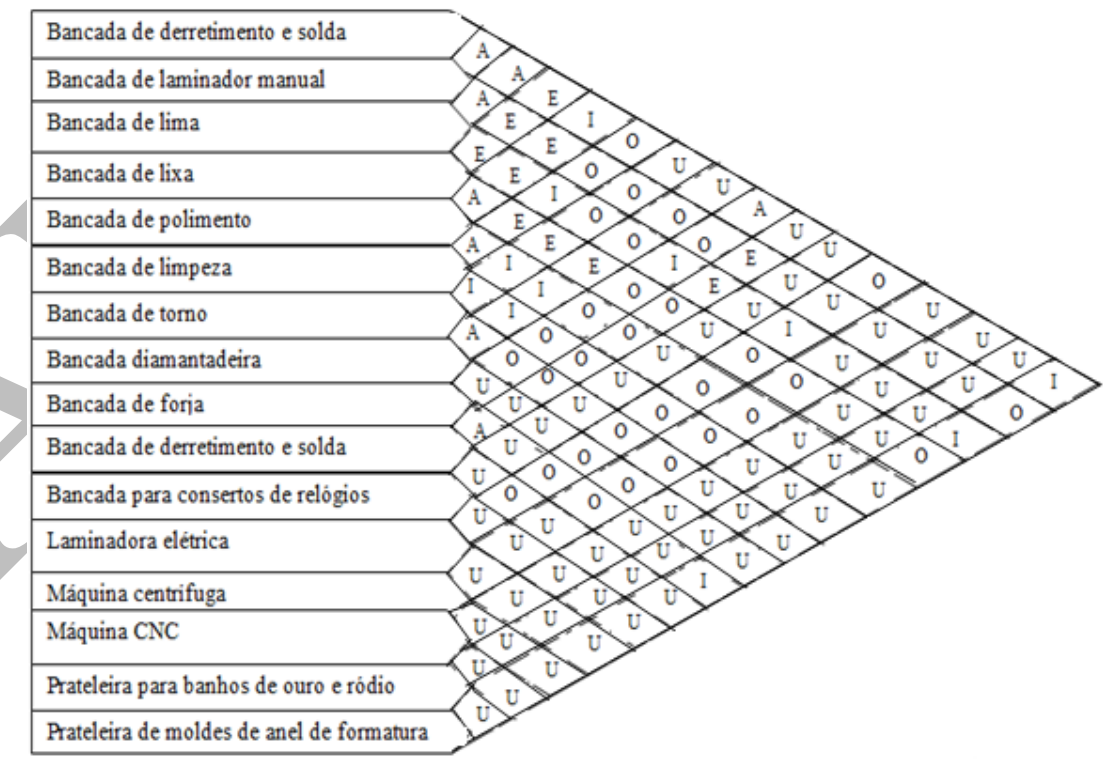

Fonte: Elaboração própria (2019). 
Pode-se observar que as atividades possuem uma proximidade considerável representada pelas letras A, E, I e O. Essas letras significam que: A - as atividades devem estar próximas; E - é muito importante que as atividades estejam próximas devido ao fluxo de operações existente entre elas; I - as atividades possuem certo fluxo de operações, e se for possível, que estejam próximas; $\mathrm{O}$ - o fluxo entre as atividades é baixo, não sendo necessário que as mesmas estejam próximas.

Contudo, as atividades representadas pela letra $U$ possuem pouca importância para o processo produtivo da organização, pois referem-se às unidades em que não existem fluxos entre elas, como por exemplo a bancada de consertos de relógios, a prateleira para banhos de ouro e ródio e a máquina $\mathrm{CNC}$ que está em desuso. Além disso, há duas torres de relógios que estão no ambiente ocupando o espaço de forma improdutiva.

d) Diagrama de inter-relação: nesta ocasião, o diagrama foi utilizado para simbolizar as atividades inter-relacionadas e integradas de acordo com sua importância e proximidade, conforme foram apresentadas na Figura 5, interligando-as sem considerar o espaço entre elas através do código em linhas, como pode ser visto na Figura 6.

Figura 6. Diagrama de inter-relação da organização com códigos em linhas

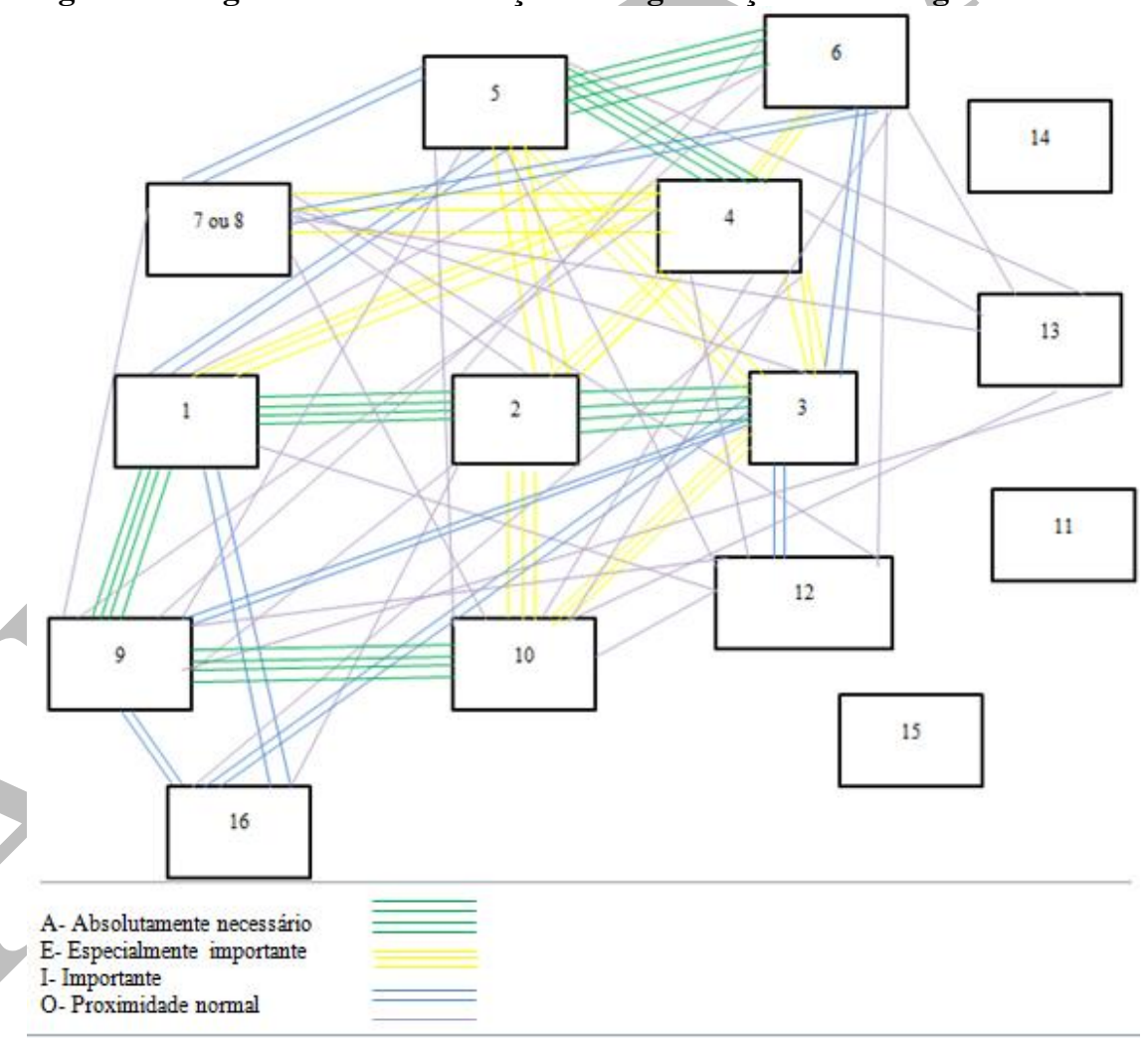

Fonte: Elaboração própria (2019).

Neste passo, as atividades foram interligadas e distribuídas de acordo com seu valor de 
proximidade. Por exemplo, 4 linhas, valor igual a 4, 3 linhas, valor igual a 3, e assim por diante. Isso indicou as atividades consideradas importantes de acordo com sua proximidade e fluxo de material entre elas. Sendo assim, a atividade que não possui linhas não possui relação com as demais atividades, como ocorreu com as UP's 11, 14 e 15.

e) Espaço necessário e disponível: o ambiente produtivo da joalheira apresenta um bom espaço físico, considerando a quantidade de equipamentos disponíveis e de pessoas que comportam nesse ambiente, com área total de $28.4 \mathrm{~m}^{2}$. Entretanto, para que o fluxo de operações seja mais eficiente, é possível otimizar mais o espaço por meio da remoção dos equipamentos obsoletos e das divisórias entre os três postos de trabalho ou abrindo passagens entre os dois postos, os quais precisam se relacionar.

Assim, inicia-se a segunda fase do método, a pesquisa, que busca inter-relacionar as atividades de acordo com o seu espaço:

f) Diagrama de inter-relação de espaços: nesta etapa, foram consideradas as medidas de cada equipamento da organização, com base no espaço disponível, de forma que o diagrama foi aplicado a fim de gerar um arranjo físico prévio, o qual pode ser observado na Figura 7.

Figura 7. Diagrama de inter-relação de espaços do ambiente produtivo

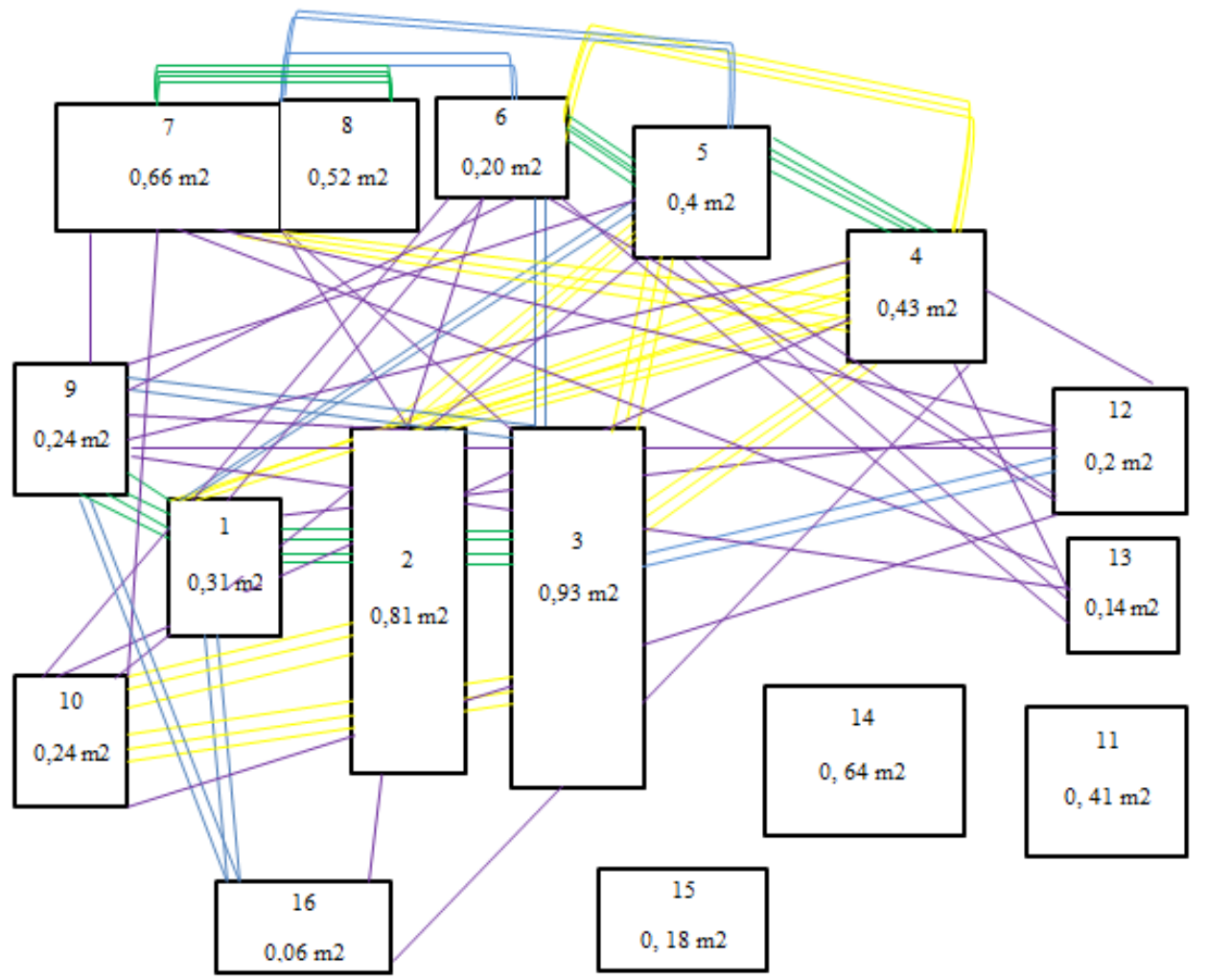

Fonte: Elaboração própria (2019).

Aqui, pode-se perceber que, com o balanceamento do espaço e dos equipamentos, as 
atividades prioritárias de proximidade foram alocadas próximas umas das outras para facilitar os processos de produção e reduzir suas distâncias. Assim, as atividades 11 e 15 por serem de pouca importância no processo, são posicionadas em um local de baixo fluxo, para que o fluxo produtivo das joias não seja afetado, tendo em vista que se trata de uma bancada de consertos de relógios e uma prateleira de banhos de ouro e ródio. Outro caso, é que a unidade 14 será removida para dar mais espaço ao ambiente, pois refere-se a uma máquina obsoleta. g) Considerações de mudanças e limitações práticas: a organização possui uma área total de produção de $28.4 \mathrm{~m}^{2} \mathrm{e}$, para fazer alterações em seu layout, quatro informações devem ser consideradas. A primeira diz respeito às limitações da instalação, pois no ambiente produtivo existe uma pia para a lavagem das mãos após o processamento das joias. No entanto, esta pia raramente é usada, pois há um banheiro fora da oficina e os funcionários preferèm utilizá-lo. Assim, uma solução para essa situação seria o isolamento desse tubo de esgoto. A segunda se refere às divisórias entre os postos de trabalho, as quais estão no ambiente apenas para separálos e que podem ser removidas para fornecer um ambiente mais amplo e conectado. A terceira informação tem relação ao destino dado aos equipamentos obsoletos. Sobre isso, há um local fora da oficina que pode ser utilizado para o armazenamento desses equipamentos, como é o caso da máquina $\mathrm{CNC}$, que está aguardando treinamento para utilização. Ainda assim, o espaço desta máquina deve ser considerado no ambiente produtivo, para que, quando estiver pronta para o uso, possa ser alocada sem interferir no espaço de outros equipamentos. Por fim, a quarta informação é que a instalação possui uma coifa de parede, a qual está fixada à tubulações no teto, devendo ser considerada no momento do rearranjo. Em suma, o ambiente produtivo está apto a mudanças e novos posicionamentos dos recursos em seu arranjo físico. $\mathrm{Na}$ última fase do método, a seleção, buscou-se avaliar as alternativas de layout propostas e selecionar a melhor para a organização:

h) Avaliação das alternativas: nesta etapa, foram organizadas três opções de layout para a joalheria, de acordo com suas limitações e necessidades. Assim, as três propostas são visualizadas na Figura 8. 
Figura 8. Layouts propostos

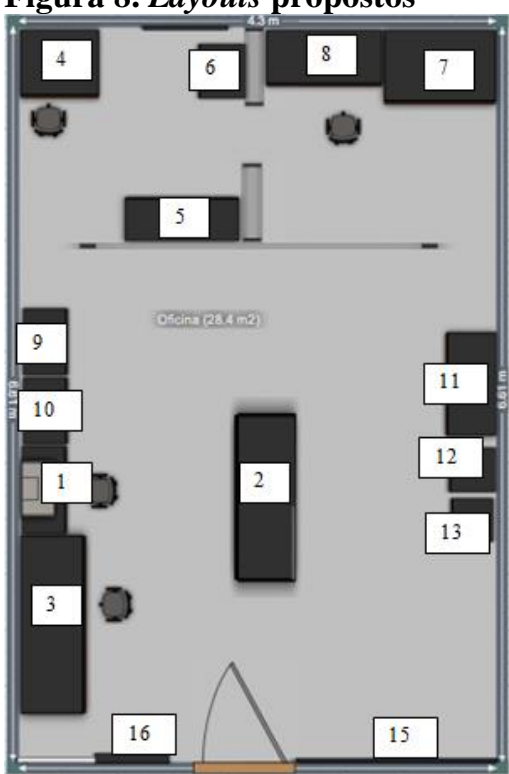

Layout proposto 1

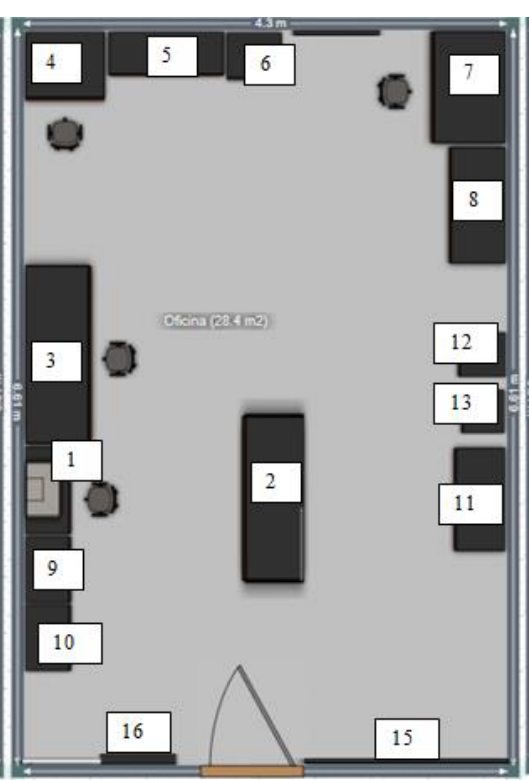

Layout proposto 2

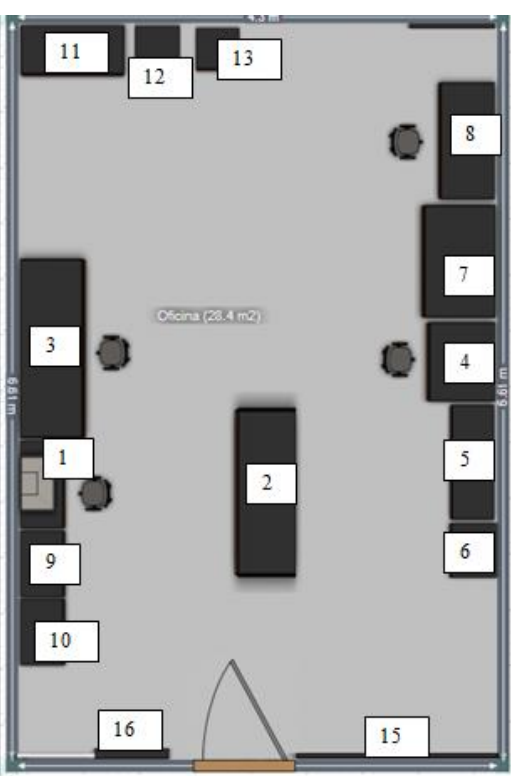

Layout proposto 3

Fonte: Elaboração própria (2019).

A primeira proposta apresentada considerou a necessidade de abrir passagens para que as estações de trabalho pudessem se relacionar mais facilmente, por isso os equipamentos dessas estações foram reposicionados para permitir um melhor fluxo de operações nos processos produtivos, não havendo muitas mudanças em outras atividades, além da remoção das torres e da máquina $\mathrm{CNC}$.

Na segunda proposta, a maioria das UP's foram reposicionadas para que atividades de grande importância e proximidade permanecessem o mais próximo possível. Nessa situação, as divisórias foram removidas, proporcionando um ambiente mais amplo e mais visível. Já na terceira proposta, as unidades foram reposicionadas de acordo com a importância da proximidade, explorando-se a ideia de posicioná-las no início do ambiente produtivo e, no final, no canto superior esquerdo, as atividades normais de proximidade e a atividade de pouca importância para o processo de produção de joias, neste caso, a bancada de consertos de relógios.

Em geral, todas as propostas consideraram as limitações do ambiente, como a coifa de parede, o isolamento do lavatório e o espaço disponível para a máquina CNC que será posicionada no futuro sem interromper os outros equipamentos.

Diante do exposto, considerando que o método SLP se encerra com a escolha da melhor alternativa, considera-se que a alternativa mais adequada para a organização é a proposta 2 , pois apresenta um ambiente mais aberto, com atividades mais organizadas e melhor distribuídas, considerando que as atividades de proximidade estão adequadas e as de pouca 
importância para os processos de produção das joias estão posicionadas em um local de baixo fluxo e facilmente acessíveis aos funcionários, sem interromper os processos de produção.

\section{Considerações Finais}

O presente estudo se propôs a analisar o ambiente produtivo de uma joalheria, buscando melhorias por meio da análise da relação entre as atividades, bem como do espaço disponível e suas limitações, de acordo com a metodologia SLP.

Nesta ocasião, foi possível identificar o arranjo físico presente na organização e como ele está organizado. Assim, observou-se que a oficina possui uma estrutura produtiva separada por Unidades de Processamento, o que permite caracterizar o arranjo físico como do tipo funcional, já que cada produto passa por diferentes tipos de processos, dependendo de suas necessidades.

No que se refere à aplicação do método SLP, foi possível observar o grau de importância e proximidade entre os equipamentos do ambiente produtivo, compreendendo o papel que cada um deles representa e a maneira como estão posicionados, refletindo no processo de produção. A partir daí, foram feitas propostas de layouts, bem como apontou-se ao final a melhor delas, respeitando as necessidades da organização em questão.

Assim, este trabalho contribui para a organização estudada, na medida em que aponta caminhos para que os fluxos de operações se tornem claros e flexíveis, aproveitando espaço e posicionando os recursos em locais acessíveis que facilitam os processos de produção, de forma a melhorar o desempenho produtivo. Ademais, destaca-se o apoio do método SLP, que se mostrou prático e de fácil compreensão, auxiliando no alcance do objetivo traçado.

Ainda assim, destaca-se como limitação certa dificuldade na aplicação do método SLP no que se refere ao diagrama de relacionamento. Em outras palavras, para a elaboração deste diagrama, foi preciso considerar a importância e a proximidade de cada atividade, a partir da observação no ambiente produtivo, o que demandou um tempo considerável para que todas as atividades fossem analisadas cuidadosamente, evitando erros e buscando favorecer as etapas posteriores do método. Isto tornou a etapa complexa e crucial para a aplicação do SLP. Finalmente, apresentam-se algumas sugestões para estudos futuros: a) analisar a aplicabilidade dos layouts propostos por meio de pesquisas de custo e indicadores de desempenho; b) replicação do estudo em outras joalherias de mesmo porte, visando à comparação entre os resultados e; c) aplicar o método SLP em outros tipos de organização. 


\section{Referências}

Cervo, A., Bervian, P., \& Silva, R. (2006). Metodologia Científica. São Paulo: Pearson Prentice Hall.

Corrêa, H., \& Corrêa, C. (2009). Administração de Produção e Operações. São Paulo: Atlas.

Erik, A., \& Kuvvetli, Y. (2021). Integration of material handling devices assignment and facility layout problems. Journal of Manufacturing Systems, 58, 59-74. https://doi.org/10.1016/j.jmsy.2020.11.015

Fahad, M., Naqvi, S. A. A., Atir, M., Zubair, M., \& Shehzad, M. M. (2017). Energy Management in a Manufacturing Industry through Layout Design. Procedia Manufacturing, 8, 168-174. https://doi.org/10.1016/j.promfg.2017.02.020

Flessas, M., Rizzardi, V., Tortorella, G., Denicol, J., \& Marodin, G. (2014). Planejamento sistemático de layout aplicado à cozinha industrial de um restaurante temático. Revista Produção em foco, 4(2), 449-480. https://doi.org/10.14521/P2237-5163201400060010

Gayam, N. R., Shanmuganandam, K., \& Vinodh, D. (2020). Layouts in production industries: A review. Materials Today: Proceedings. https://doi.org/10.1016/j.matpr.2020.10.191

Gil, A. (2009). Como elaborar projetos de pesquisa. São Paulo: Atlas.

Giraldeli, F., Ferreira, T., Gomes, P., Chiroli, D., Zola, F,, \& Aragão, F. (2018). Estudo do fluxo de processo para readequação de layout em uma empresa do segmento elétrico. Exacta, 16(4), 79-91. https://doi.org/10.5585/Exacta.v16n4.8020

Godoy, A. (1995). Pesquisa qualitativa: tipos fundamentais. Revista de Administração de Empresas, 35(3), 20-29. https://doi.org/10.1590/S0034-75901995000300004

Lermen, F. H., Campos, R. V. M., Coelho, T. M., Matias, G. M., \& Echeveste, M. E. S. (2020). A proposal for restructuring the layout of continuous freezing tunnels of fresh sausages. Gestão \& Produção, 27(1), e2969. https://doi.org/10.1590/0104-530x2969-20

Liu, K-H., Hwang, S-L., Hsieh, M-H., Liang, S-F. M., \& Chuang, C-F. (2016). Systematic layout planning in human-system interface: An evaluation of alarm displays with spatial proximity for accidents diagnosis of advanced boiling water reactor. International Journal of Industrial Ergonomics, 51, 30-42. https://doi.org/10.1016/j.ergon.2014.12.014

Moreira, D. (2012). Administração da Produção e Operações. São Paulo: Cengage Learning.

Muther, R. (2012). Planejamento do layout: Sistema SLP. São Paulo: Imam.

Ojaghi, Y., Khademi, A., Yusof, N. M., Renani, N. G., \& Hassan, S. A. H. B. S. (2015). Production Layout Optimization for Small and Medium Scale Food Industry. Procedia CIRP, 26, 247-251. https://doi.org/10.1016/j.procir.2014.07.050

Slack, N., Brandon-Jones, A., \& Johnston, R. (2018). Administração da produção. $8^{\text {a }}$ ed. São Paulo: Atlas. 
Slack, N., Chambers, S., \& Johnston, R. (2009). Administração da produção. $3^{\mathrm{a}}$ ed. São Paulo: Atlas.

Van Donk, D. P., \& Gaalman, G. (2004). Food Safety and Hygiene: Systematic Layout Planning of Food Processes. Chemical Engineering Research and Design, 82(11), 1485 1493. https://doi.org/10.1205/cerd.82.11.1485.52037

Vieira, N., Fernandes, F., Cortez, L., Nunes, A., \& Araújo, L. (2014). Aplicação do método SLP para melhoria do arranjo físico: estudo de caso em uma empresa do ramo alimentício. Curitiba: Revista Latino-Americana de Inovação e Engenharia de Produção, 2(3), 74-85. https://doi.org/10.5380/relainep.v2i3.38415

Yang, T., Su, C., \& Hsu, Y. (2000). Systematic layout planning: a study on semiconductor wafer fabrication facilities. International Journal of Operations \& Production Management, 20, 1359-137. https://doi.org/10.1108/01443570010348299

Yin, R. (2010). Estudo de caso: planejamento e métodos. Porto Alegre: Bookman. 